\title{
Carnets
}

Revue électronique d'études françaises de l'APEF

Première Série - 1 Numéro Spécial | 2009

Cultures littéraires : nouvelles performances \& développement

\section{Reinventando o "francesismo": estratégias de ensino e de leitura}

Álvaro Manuel Machado

\section{CpenEdition}

Journals

Edição electrónica

URL: http://journals.openedition.org/carnets/3181

DOI: 10.4000/carnets.3181

ISSN: 1646-7698

Editora

APEF

Edição impressa

Data de publição: 1 Junho 2009

Paginação: 9-16

\section{Refêrencia eletrónica}

Álvaro Manuel Machado, «Reinventando o "francesismo": estratégias de ensino e de leitura », Carnets [Online], Première Série - 1 Numéro Spécial | 2009, posto online no dia 14 junho 2018, consultado o 30 abril 2019. URL : http://journals.openedition.org/carnets/3181; DOI : 10.4000/carnets.3181

\section{(c) (i) ()ㅜㄹ}

Carnets est mis à disposition selon les termes de la licence Creative Commons - Atribution - Pas d'utilisation commerciale 4.0 International. 


\section{REINVENTANDO O "FRANCESISMO": \\ Estratégias de ensino e de leitura}

ÁlVARO MANUEL MACHADO

Universidade Nova de Lisboa

\section{Resumo}

Este texto aborda a questão da imagem e da influência da França como herança de um "francesismo" caracteristicamente oitocentista, não só na literatura e na cultura portuguesas em geral, mas também no ensino e na prática da leitura. Sob uma óptica comparatista, o estudo percorre essas imagens, interrogando-as no âmbito do presente e também de um futuro próximo. ${ }^{1}$

Palavras-chave: Francesismo, Literatura francesa, Literatura comparada Mots-clés: "Frenchism", Littérature française, Comparative literature

\footnotetext{
${ }^{1}$ Resumo da responsabilidade dos editores.

Álvaro Manuel Machado, "Reinventando o "francesismo": estratégias de ensino e de leitura", Carnets, Cultures littéraires: nouvelles performances et développement, no spécial, automne / hiver 2009, pp. 9-16. 
Num Fórum como este, naturalmente voltado para o futuro (o que é, sem dúvida, altamente positivo), com predominância de reflexões, mais ou menos sistemáticas, sobre as novas tecnologias da era digital e as mais recentes teorias pedagógicas, talvez eu esteja deslocado ou pareça um dinossauro (não excelentíssimo, claro...). Quase a sair de cena, depois de mais de trinta e cinco anos de carreira universitária, debato-me com o meu superego quando sinto incivilizada vontade de excomungar essa enfadonhamente burocrática invenção do ensino universitário na comunidade europeia a que se chama Reforma de Bolonha ou Tratado de Bolonha (o que me faz lembrar, permitam-me dize-lo, qualquer coisa de indigesto com molho "à bolonhesa"...). Um tratado todo concebido sob a égide da língua inglesa, da cultura e da mentalidade anglo-saxónicas, que me leva a fecharme na minha torre de marfim de "afrancesado" impenitente e a evocar o destino chateaubrianesco do "último abencerragem"...

Por consequência, devo honestamente dizer desde já, em jeito de intróito, que esta minha comunicação (ou breve conferência, se preferirem) embora sem diatribes polémicas tem um carácter muito mais de arriscado (e contestável) testemunho pessoal, predominantemente auto-reflexivo, afastando-se da reflexão sistemática de cariz estritamente ou sobretudo pedagógico. No centro, abordada em termos comparatistas, estará a questão da imagem e da influência da França como herança de um "francesismo" caracteristicamente oitocentista, não só na literatura e na cultura portuguesas em geral, mas também no ensino e na prática da leitura, elementos que tentarei perspectivar no âmbito do presente e também de um futuro próximo.

\section{O "fantasma" do "francesismo", do século XIX ao século XX, em Portugal. "Francesismo" e nacionalismo}

Começo por evocar o testemunho de um escritor português, maior entre os maiores, que ao longo da sua vida reflectiu arduamente sobre os problemas da identidade portuguesa, fundada em oposições simbólicas, sem nunca se deixar contaminar por modas, francesistas ou outras : Miguel Torga. Já abordei, em diferentes ocasiões, a relação de Torga com a cultura e a literatura francesas ${ }^{2}$. Aqui, interessa-me relevar a relação entre Torga e Montaigne a nível de uma certa aura do intelectual, situado entre a filosofia e a literatura, plenamente entregue à sua missão de pensar, aura esta que é herança sobretudo da cultura francesa em Portugal desde o século XVIII, expandindo-se particularmente no século XIX e deste passando para o século XX (bastará referir, por exemplo, o caso de Vergílio Ferreira). Diz Torga no segundo volume do seu Diário, a propósito da leitura dos

\footnotetext{
${ }^{2}$ Cf., entre outros, o texto "Miguel Torga", Raul Brandão e a herança pós-romântica de Victor Hugo", in Álvaro Manuel Machado, Do Ocidente ao Oriente. Mitos, imagens, modelos, Lisboa, Presença, 2003, pp. 219/226.
} 
Essais, em especial do capítulo XXIII, intitulado "De la coustume, et de ne changer aisément une loy reçue" :

Bons tempos estes em que um intelectual podia isolar-se na sua torre, e consumir a preguiça a anotar largos exemplos e a tirar breves e subtis conclusões. Bons tempos estes, sem pedagogias nem psicologias [... $]^{3}$

Torga exalta aqui, sobretudo, a solidão do pensador, solidão entre todas criativa, mas, note-se, não tanto a solidão em si mesma (Torga propõe antes, em particular no seu Diário, aquilo a que, graças principalmente a Sartre, se chamou engagement do intelectual na história e na sociedade): mais propriamente, uma solidão que se enraíze na independência do pensamento e numa incessante procura de ideias novas, livres das tais peias a que ele chama de "pedagógicas" e "psicológicas"... Sagração do intelectual, portanto, como imagem da própria França, projectada desde há muito na cultura portuguesa em geral, com tudo o que a cultura, como fenómeno múltiplo e complexo, implica: vida social, formação de elites, literatura, ensino, ideologia. E aqui não posso deixar de evocar o "fantasma" do chamado "francesismo" em Portugal, que se agigantou sobretudo no século XIX e, atravessando, em vários domínios, o século XX, ainda sobrevive (pelo menos como objecto de estudo sempre controverso) neste princípio do século XXI.

Vejamos. Já por variadíssimas vezes estudei o fenómeno da formação e expansão do "francesismo" na cultura portuguesa em geral e na literatura portuguesa em particular, fenómeno que teve evidentes reflexos no sistema de ensino de línguas estrangeiras no nosso país. Como fiz notar, num ensaio publicado há vinte e quatro anos, $O$ "francesismo" na literatura portuguesa, se, para lá da própria recusa do iberismo, a imagem da França se tornou "francesismo" foi essencialmente porque, sobretudo com o século XIX, a França era considerada o centro cosmopolita por excelência, núcleo central da cultura e da civilização europeias, exercendo uma incomparável função mediadora entre o Norte e o Sul (teoria defendida por Madame de Staël, Victor Hugo, Edgar Quinet, Taine e tantos outros, além de, entre nós, muito particularmente, Oliveira Martins). Em suma : a imagem da França levou ao "francesismo" em Portugal sobretudo porque se idealizou a França como sendo o contrário do provincianismo, quer literário quer social ${ }^{4}$. Ora, quando Eça (que, como se sabe, "inventou" a expressão "francesismo" no seu célebre texto assim intitulado e publicado postumamente, em 1912, na colectânea Últimas páginas) diz que Portugal é um país "traduzido do francês em calão", está a levantar um problema cultural (e também

\footnotetext{
${ }^{3}$ Miguel Torga, Diário II, 2ª edição, revista, Coimbra, 1949, p. 84.

${ }^{4}$ Cf. Álvaro Manuel Machado, O "francesismo" na literatura portuguesa, Lisboa, ICALP, "Biblioteca Breve", 1984, p. 15 e segs..
} 
educacional, como com extrema justeza notou Maria Hermínia Amado Laurel ${ }^{5}$ ) que é bem tipicamente (e diria até intemporalmente) português : a imitação, mais ou menos servil, do estrangeiro. À qual se contrapõe, aliás, uma exaltação quase paranóica do "casticismo" português, um nacionalismo enraizado sobretudo no arcaico mundo rural e na heroicidade dum mítico passado glorioso. Exemplo paradigmático desta atitude no século XIX, reagindo contra o "francesismo", é o de Camilo. Entre muitos textos de violenta diatribe, cite-se, pela linguagem verborreica, o prefácio ao romance $A$ enjeitada (1866), evocando grandiloquentemente o Portugal heróico das lutas contra as tropas invasoras de Napoleão:

Ó quadra saudosa de patriotismo! ó guerra dos franceses! ó heróico Portugal no tempo em que tu eras tão português, tão façanhoso contra os franceses [...]! Ó tempo, tempo em que nem ainda as francesas se podiam tolerar neste abençoado torrão, donde pululavam Viriatos como tortulhos bravos quando chove! [...] Tão perto de nós esses dias de febril glória! Meio século apenas! [...] - e já hoje todos trajamos à francesa, pensamos francesmente... ${ }^{6}$

A verdade é que (incluindo o próprio Camilo), para lá do casticismo nacionalista, em termos culturais, linguísticos e literários genéricos, pode afirmar-se com rigor que a influência da França predominou até, pelo menos, aos anos 70 do século passado, criando várias versões de "francesismo". Ou seja : predominou como expressão de uma cultura e de uma língua estrangeiras enraizadas nas instituições portuguesas sobretudo desde o século XIX. O fenómeno foi até estudado cientificamente. A este propósito, será oportuno referir a análise de surpreendente precisão estatística que constitui o estudo monográfico de Manuel Bernardes Branco (1832-1900) na sua obra monumental em cinco volumes intitulada Portugal e os estrangeiros, publicada em Lisboa entre 1879 e 1895. Nela constatamos facilmente que a imagem da França, na sua complexa difusão, ultrapassa de longe todas as imagens dos outros países estrangeiros. Obviamente, utilizo aqui a palavra imagem no sentido primordial de imaginário (de que adiante falarei mais em pormenor), mas também no sentido concreto de relação cultural e institucional. Paralelamente ao estudo sistemático de Manuel Bernardes Branco, deveremos referir uma outra obra monumental de síntese que vai no mesmo sentido, a de José Silvestre Ribeiro (1807-1891), História dos estabelecimentos scientificos, litterarios e artisticos de Portugal nos sucessivos reinados da monarchia, publicada pela Real Academia das Ciências, em 18 volumes, entre 1871 e 1893, a qual chama também a atenção para a nítida prevalência da língua e da literatura francesas

\footnotetext{
${ }^{5}$ Maria Hermínia Amado Laurel, "Estudos literários franceses em Portugal : percursos entre o passado e o presente", in Intercâmbio, revista do Instituto de Estudos Franceses da Faculdade de Letras da Universidade do Porto, no 12, Porto, 2007, p. 35.

${ }^{6}$ Camilo Castelo Branco, A enjeitada, 4를. ed., Lisboa, Parceria A. M. Pereira, 1902, pp. 9-10.
} 
na formação dos estabelecimentos culturais em Portugal. Note-se como José Silvestre Ribeiro sublinha então, desde o prefácio, a importância da estatística: tomando sobretudo como exemplos a França e a Inglaterra, refere que, contrariamente a Portugal, aí "toma-se nota de tudo quanto interessa examinar e saber: a estatística, nos seus variados aspectos e domínios, é uma realidade [...]."7

Com a Geração de 70 e o chamado "terceiro romantismo", a influência dos grandes modelos literários românticos franceses mescla-se com outras influências estrangeiras, sobretudo a do romantismo alemão, que fora até então quase desconhecido e raramente estudado a nível da história das ideias filosóficas e da teorização literária, embora as obras desses autores sejam quase sempre lidas em traduções francesas. No próprio período de formação, em Coimbra, as leituras de Balzac, Hugo, Musset, Michelet misturam-se com, entre outras, as de Goethe ou Heine, como nos testemunhará mais tarde Eça no célebre texto sobre Antero "Um génio que era um santo", incluído postumamente nas Notas contemporâneas. Mas a imagem da França prevalece: lembremos, em relação a Antero, muito influenciado por Michelet na fase das Conferências do Casino, que ao conceito de decadência de Portugal é contraposta uma ideia de messianismo revolucionário inspirado na insurreição da Comuna de Paris. E Michelet foi para Antero uma espécie de Deus. Quando, em 1866, Antero parte para Paris, visita Michelet e, já depois das Conferências do Casino, em Agosto de 1877, num período de plena maturidade criadora, Antero, de novo em Paris, escreve um breve ensaio em que confessa ser "um dos seus discípulos portugueses". Paralelamente, uma outra imagem da França se expande em pleno período da Geração de 70, imagem que vai prolongar-se para lá do próprio fin de siècle invadindo o século $\mathrm{XX}$ : a da mítica cidade de Paris, mitologia baudelairiana tão genialmente analisada por Walter Benjamim. E é essa, sem dúvida, uma metamorfose do "francesismo" em Portugal que mais profundamente penetrou no imaginário de tantas gerações depois da Geração de 70.

\section{2. "Francesismo", literatura francesa e Literatura Comparada: ideologia, estética e imaginário}

Passamos, assim, à análise de um outro aspecto fundamental relativo à fixação da imagem de um país estrangeiro . a mitologia das grandes cidades, elemento fulcral na formação da imagem da França em Portugal (e não só). Refiro-me, como é óbvio, à mitologia de Paris, desde a Idade Média e com particular relevo a partir dos séculos XVIII e XIX, fundada em quatro factores : a dimensão urbana e demográfica; a dimensão intelectual (Paris centro da civilização europeia, capital das "lumières" e das artes); a dimensão

\footnotetext{
7 José Silvestre Ribeiro, Historia dos estabelecimentos scientificos, litterarios e artisticos de Portuga nos sucessivos reinados da monarchia, Lisboa, Tip. da Real Academia das Ciências, 1871-1893, vol. I, p. V.
} 
histórica (Paris símbolo das revoluções, sobretudo desde a Revolução de 1789); a dimensão hedonista (Paris capital do prazer e da libertinagem). Dessa mitologia (de Paris, mas também de outras grandes cidades, como Londres ou, fora da Europa, Nova lorque) se alimenta a aprendizagem da língua e da cultura, se alimenta, em suma, todo o imaginário, fundindo ideologia e estética.

Chegados a este ponto, permitam-me uma abordagem essencialmente comparatista (que é a minha coutada há muitos anos...) do fenómeno do "francesismo" ou do que dele resta, sem esquecer, claro, hipotéticas estratégias de ensino e de leitura projectadas no futuro. Abordagem aqui centrada na imagologia, a qual, como se sabe, é um método de investigação enraizado na chamada "escola francesa" e agora aproximado (por vezes abusivamente) dos chamados Cultural Studies de origem anglo-saxónica.

Como se depreende facilmente, a imagem de um país estrangeiro é, em grande parte, estereotipada. Todavia, para lá dessa limitação, ela deve ser estudada (e ensinada) como uma "verdade", constituindo aquilo que, de facto, ela essencialmente constitui, ou seja : um conjunto de elementos vasto e complexo, a que se chama imaginário. Este imaginário está, obviamente, sujeito a transformações histórico-sociais, actualizando constantemente a representação do Outro, revelando um espaço ideológico e, simultaneamente, códigos estéticos. Isto aplicou-se, claro, ao século XIX, cristalizando-se então a imagem da França através da própria mitologia de Paris, acima referida. Esta mitologia tomou formas por vezes extremamente estereotipadas na literatura portuguesa, desencadeando atitudes culturalmente conflituosas. Para voltarmos a Eça, lembremos, no final de $A$ cidade $e$ as serras, o episódio do regresso de Zé Fernandes a Paris, arrastando "dias de imenso tédio". Zé Fernandes mergulha no seu "doce Bairro Latino" e, subindo as escadarias da Sorbonne, indigna-se, aos berros, contra os estudantes (precursores dos de Maio de 68...) que contestam um velho mestre a dar aulas num anfiteatro, sendo chamado por um estudante que ele qualifica de "abortozinho amarelado e sebento, com longas melenas" de "Sale maure!' e decidindo, depois de uma heróica rixa à antiga portuguesa, abandonar definitivamente essa "fastidiosa" cidade, monstro de civilização ${ }^{8}$.

Mas deixemos o século XIX e a fixação da imagem da França através do já analisado "francesismo" descrito por Eça. Será oportuno, creio, repensar a relação entre tempo histórico e literatura, de maneira a que a imagem do país (neste caso a da França), veiculada pela aprendizagem da língua e pelo incentivo da leitura, não se torne esclerosada. Algumas questões básicas se levantam. O que é um acontecimento literário? O que é uma geração? Aos tempos dos acontecimentos e da estrutura da história acrescentam-se o tempo ritual ou cíclico, profundamente estudado por Mircea Eliade, e o tempo plural, para o

\footnotetext{
${ }^{8}$ Eça de Queirós, A cidade e as serras, Lisboa, ED. Livros do Brasil, s/d, pp. 243/44.
} 
qual já Henri Focillon, em Vie des formes (1943), chamava a nossa atenção, fazendo notar o carácter simultaneamente actual e inactual da obra de arte. Tempo plural que posteriormente foi estudado pelo historiador Fernand Braudel na sua célebre teoria da "longue durée", ou seja, dos três tempos, exposta em Écrits sur l'histoire (1969, 2o volume, 1990): o tempo longo das mentalidades, o tempo médio ou cíclico da economia e o tempo curto do acontecimento político. O que nos leva à ideia de que deveremos analisar o fenómeno literário (e através dele o fenómeno da imagem de um país estrangeiro) simultaneamente através do tempo "longo" e do tempo simbólico instaurado pela obra e pela cultura que ela representa.

Outras questões surgem do confronto entre tempo e literatura : o que é uma transição, uma ruptura, uma época? Como definir a alternância tradição/inovação, antigo novo, na formação e evolução da imagem de um país estrangeiro? A este nível, a literatura como instituição deverá ser estudada, para utilizar os termos de Pierre Bourdieu em Les règles de l'art. Genèse et structure du champ littéraire (1992), como um "champ littéraire", passando pela análise de realidades sociológicas como o fenómeno editorial. Deveremos utilizar este conceito sobretudo em estudos de imagologia, relacionando a literatura com as grandes correntes de mentalidades e de sensibilidades ou confrontando-a com o processo civilizacional. Note-se que as investigações de Bourdieu chamaram a atenção para fenómenos, não de crítica, mas de legitimação da literatura. Daí a reflexão sobre o conceito de cânone ou de literatura canónica, quer dizer, o corpus de textos cujos valores estéticos, ideológicos e culturais representam, para determinada sociedade, paradigmas da sua cultura, em suma, os "clássicos", como, por exemplo, Montaigne para a cultura francesa.

Para além destas questões de ordem geral, há a necessidade de ensinar a literatura que veicula a imagem de um país estrangeiro a nível daquilo a que se pode chamar a magia da palavra escrita, ou seja, a palavra criando significações, microvisões do mundo, invenções vocabulares. Ao fim e ao cabo, é da palavra escrita que o escritor vive. É precisamente disso que nos fala Sartre, paradigma do intelectual francês, nesse livro admirável entre todos os que publicou intitulado simplesmente Les mots (1964). Lembro uma passagem em que evoca as suas primeiras leituras na casa familiar e, como dizia Proust, descobre a "vraie vie" da literatura:

Nos visiteurs prenaient congé, je restais seul, je m'évadais de ce banal cimetière, j'allais rejoindre la vie, la folie des livres. II me suffisait d'en ouvrir un pour y redécouvrir cette pensée inhumaine, inquiète dont les pompes et les ténèbres passaient mon entendement, qui sautait d'une idée à l'autre, si vite que je lâchais pris, cent fois par page, et la laissais filer, étourdi, perdu. J'assistais à des événements que mon grand-père eût certainement jugés invraisemblables et qui, pourtant, avaient 
l'éclatante vérité des choses écrites.[...]. J'avais trouvé ma religion: rien ne me parut plus important q'un livre. La bibliothèque, j'y voyais un temple. ${ }^{9}$

Aproveitemos este hino sartriano à literatura, esta sagração da biblioteca e, concomitantemente, do intelectual envolto na sua aura (elemento inicial da nossa breve reflexão), para concluir, arrumando algumas ideias dispersas sobre "francesismo", imagem da França e estratégias de ensino e de leitura.

Se é verdade que em Portugal tem esmorecido, sobretudo nos últimos cinco ou dez anos, o estudo da língua e da literatura francesas em Portugal (o que, aliás, também acontece em França relativamente à língua e à cultura portuguesas), também é verdade, parece-me, que a relação cultural entre os dois países é cada vez menos "assimétrica" (parafraseando Eduardo Lourenço), o que se torna altamente positivo. Talvez a França, ao perder o seu imperialismo linguístico e cultural, se tenha tornado menos altaneira. E será então agora a altura de a defender com a heroicidade de um cavaleiro andante, pura e simplesmente porque a França continua a sintetizar em si toda a cultura europeia.

Por outro lado, retomando o tema central desta breve reflexão, se é verdade que o "francesismo" de que falava Eça não passa, actualmente, de um bizarro objecto de estudo, ele poderá ajudar-nos decisivamente a compreender a imagem da França no passado e no presente, poderá ser reinventado, integrando-se no nosso imaginário actual. Não se trata de saudosismos fáceis. Trata-se de não permitir que, no ensino e em particular no ensino da cultura e da literatura francesas, se instale, se institua a amnésia como mitificação fanática do presente e do futuro, excluindo toda a relação com o que nos formou no mais profundo de nós mesmos. Trata-se, paralelamente, de preservar e incentivar essa errância supremamente fascinante que é a leitura, como muito bem disse um grande escritor e pensador francês contemporâneo, Pascal Quignard, no seu livro Les Ombres errantes (2002) : "Il y a dans lire una attente qui ne cherche pas à aboutir. Lire c'est errer. La lecture est l'errance." ${ }^{10}$ Trata-se, enfim, de propor a releitura dessa tão variada e tão apaixonantemente mediadora cultura francesa, dos trovadores a Rabelais, de Rousseau a Victor Hugo, Baudelaire ou Proust, destes a Sartre ou Pascal Quignard. De facto, em última análise, trata-se apenas de manter a França no horizonte de expectativa (como diria Jauss) de todos nós, lucidamente, sem galomania nem galofobia. Apenas a "douce France" de sempre.

\footnotetext{
9 Jean-Paul Sartre, Les mots, Paris, Gallimard, col. «Folio», 1975, pp. 47-53.

${ }^{10}$ Pascal Quignard, Les ombres errantes, Paris, Bernard Grasset, 2002, p. 50.
} 